\title{
Sensitivity of indicators used in cost-volume-profit analysis
}

\author{
Carmen-Elena Stoenoiu ${ }^{1, *}$ \\ Technical University of Cluj-Napoca, Department Electrical Machines and Drives, Cluj-Napoca, România
}

\begin{abstract}
The need for cost-volume-profit analysis (CVP) starts from the need to optimize and manage costs due to unforeseen events that accompany economic activity in all areas. In this paper, the dependency relationship between the three cost-volume-profit indicators was analyzed to highlight the need to permanently track and optimize these variables so that managers' decisions can be supported by adaptive analyzes to concrete needs. The study also includes a sensitivity analysis that has shown that the magnitude and meaning of changes occurring when changes occur to one or more variables may be different due to direct and inverse relationships that are established between these variables.
\end{abstract}

\section{INTRODUCTION}

In the economic activity of any one enterprise, there is the operational risk due to dependent and independent variables that influence the result of the exploitation activity and ultimately the profitability. Adaptation of the enterprise to the present is thus a condition for survival but also for development, and the ability of the enterprise to cope with the economic risk is the condition to reach profitability when the lowest costs are obtained [1]. When firms want to maintain their production capacity, variable costs are those on which managers will focus because fixed costs are mostly committed to becoming uncontrollable [2], [3].

For this, there are several studies and researches demonstrating the importance of anticipating costs as well as the advantages and disadvantages of costing models [4] - [6]. This is the case for researchers who come up with general arguments about how to understand costs [7], which supports the role of complexity in cost-increasing operations [8], or who argue that increasing varieties and heterogeneity in the product mix will most often lead to a negative impact on costs and on operational performance [5], [9].

Organizational agility and dynamic capabilities of the enterprise (adaptation to change, innovation and creating a favourable market for customers and unfavourable to competition) are two topics debated in recent studies and research, this being seen as helping to prioritize the consistency between strategy, structure and business environment [10], [11].

Various studies show that managers are inclined to use transfer prices that are not at the total cost level [12] while others advocate their alignment to total costs [13]. Although the former affects tax levels and managerial decisions, accounting and cost management have shown that the use of transfer pricing at total costs affects efficiency not stimulating the increase in production
[12]. Different levels of production capacity utilization and arbitrary cost allocations often impede the correct cost allocation, which may affect the sales level, ie the expected profit [14] - [17]. Cost behaviour is different depending on the product, and when costs increase more than decreases in volume production, managers feel they are entitled to limit production [18] - [20]. Cost behaviours can be studied through cost - volume - profit analysis (CVP) that allows highlighting changes that may occur in the mix of product mix, sales volume, or profits through the margin of safety [21].

The purpose of this research was to identify the variables that affect a company's profit and then to observe the dependency relationship between these variables. CVP analysis allowed, through 21 cases studied, to demonstrate the existence of causal relationships between variables, and sensitivity analysis determined the magnitude and meaning of variation of a variable when changing another variable.

\section{MATERIALS AND METHODS}

The CVP analysis has identified relationships of dependence that exist between cost, volume or level of activity and profit. The values taken in the study are presented in Table 1.

This analysis is required because, in a company's activity, volume fluctuations of activity occur that cause changes within fixed and variable costs or sales price changes (only we can sell at the same price or the same amount), which ultimately can affect the profit of companies.

The equation of profit used in this article is given by the following calculation formula, (1):

$$
P=S P \times Q-V C \times Q-T F C
$$

carmen.stoenoiu@emd.utcluj.ro 
Where: P - profit; SP - sales price per unit of product; Q - the number of units produced and sold; VC - variable cost per unit of product; TFC - total fixed cost.

This CVP analysis was needed to calculate the breakpoint (zero or critical point), that is, the quantity (number of units) to be produced and sold for the company to fully cover its costs without profit or loss.

Table 1. Quantitative and valuable state of CVP indicators.

\begin{tabular}{|c|c|c|c|c|c|}
\hline $\begin{array}{l}\text { No. } \\
\text { cases }\end{array}$ & $\begin{array}{c}\text { Quantity } \\
\text { [Pcs.] }\end{array}$ & $\begin{array}{c}\text { Selling } \\
\text { price } \\
\text { per unit } \\
{[\text { RON/Pes.] }}\end{array}$ & $\begin{array}{c}\text { Variable } \\
\text { cost } \\
\text { per unit } \\
\text { RON/Pcs.] }\end{array}$ & $\begin{array}{c}\text { Total } \\
\text { fixed } \\
\text { cost } \\
{[\text { RON] }} \\
\end{array}$ & $\begin{array}{l}\text { Profit } \\
\text { [RON] }\end{array}$ \\
\hline 1 & 1,000 & 40.00 & 24.40 & $10,000.00$ & $5,600.00$ \\
\hline 2 & 1,200 & 40.00 & 23.42 & $10,000.00$ & $9,900.00$ \\
\hline 3 & 1,400 & 40.00 & 23.07 & $10,000.00$ & $13,700.00$ \\
\hline 4 & 1,600 & 40.00 & 24.88 & $10,000.00$ & $14,200.00$ \\
\hline 5 & 1,800 & 40.00 & 25.72 & $10,000.00$ & $15,700.00$ \\
\hline 6 & 2,000 & 38.00 & 25.60 & $10,000.00$ & $14,800.00$ \\
\hline 7 & 2,200 & 38.00 & 27.82 & $10,000.00$ & $12,400.00$ \\
\hline 8 & 2,400 & 38.00 & 29.08 & $10,000.00$ & $11,400.00$ \\
\hline 9 & 2,600 & 38.00 & 28.92 & $10,000.00$ & $13,600.00$ \\
\hline 10 & 2,800 & 38.00 & 28.36 & $10,000.00$ & $17,000.00$ \\
\hline 11 & 3,000 & 36.00 & 27.80 & $10,000.00$ & $14,600.00$ \\
\hline 12 & 3,200 & 36.00 & 32.13 & $10,000.00$ & $2,400.00$ \\
\hline 13 & 3,400 & 36.00 & 33.03 & $10,000.00$ & 100.00 \\
\hline 14 & 3,600 & 36.00 & 33.19 & $10,000.00$ & 100.00 \\
\hline 15 & 3,800 & 36.00 & 32.95 & $10,000.00$ & $1,600.00$ \\
\hline 16 & 4,000 & 34.00 & 32.50 & $10,000.00$ & $-4,000.00$ \\
\hline 17 & 4,200 & 34.00 & 32.81 & $10,000.00$ & $-5,000.00$ \\
\hline 18 & 4,400 & 34.00 & 32.36 & $10,000.00$ & $-2,800.00$ \\
\hline 19 & 4,600 & 34.00 & 32.22 & $10,000.00$ & $-1,800.00$ \\
\hline 20 & 4,800 & 34.00 & 32.38 & $10,000.00$ & $-2,200.00$ \\
\hline 21 & 5,000 & 32.00 & 32.00 & $10,000.00$ & $-10,000.00$ \\
\hline
\end{tabular}

Since the managers are concerned to achieve a higher sales level than the critical amount, the margin of safety has been calculated (how close it is to the equilibrium level). The safety margin was obtained by the difference between the expected sales level and the critical point sales, (2).

$$
M S=E S-B E S
$$

Where: MS - The margin of safety; ES - Expected sales; BES - Break-even sales. to (3):

The equation of profit (1) can be rewritten according

$$
P=(S P-V C) \times Q-T F C
$$

From rewriting the profit equation using Eq. (3) we get the marginal contribution per unit of product as the difference between the selling price and the unitary variable cost, (4).

$$
P=C m \times Q-T F C
$$

Where: Cm - Contribution margin per unit.
The marginal contribution per unit measures the value of the incremental profit generated by the sale of an additional unit. This may not be obvious at first glance, but with this indicator, we can see what happens when sales and production grow with one unit.

The company may benefit from incomes equal to the sales price, but it often involves increased costs equal to the variable cost per unit. Fixed costs are not affected by changes in production volume, so they do not affect the incremental profit associated with the sale of an additional unit. If we multiply the contribution margin per unit by the number of units sold, we get the total contribution margin.

If we solve the profit equation for the number of sales in units (Q), we obtain a formula that allows us to calculate the unit sales (quantity) needed to attain specified profit (USNASP) or profit target, according to (5):

$$
\text { USNASP }=(P+T F C) / C m
$$

Finally, it was necessary to carry out a sensitivity analysis to determine the effect of variation of an indicator on another indicator, both in size and level of influence (direct or inverse). The coefficient of variation used in the sensitivity analysis is within $\pm 1 \%, \pm 5 \%$, $\pm 10 \%$. The sensitivity analysis was performed by studying the variance of all existing variables in case 10 (see Table 1, when the profit is the maximum). For this, the relative diminution and the relative deviation of the variables were calculated. Relative diminution was obtained using (6):

$$
X^{\prime}=X(100 \%+a)
$$

Where: $X^{\prime}$ - the variable that suffered a relative decrease from baseline; $\mathrm{X}$ - the variable in the initial state; $\mathrm{a}$ coefficient of variation.

Later, the relative change of a variable from itself was determined, according to (7):

$$
\mathrm{X}^{\prime \prime}=\left(X^{\prime}-X\right) / X^{\prime}
$$

Where: $\mathrm{X}^{\prime \prime}$ - the relative change of a variable from the value of that variable obtained from the relative decrease.

By sensitivity analysis, it was desired to know the meaning and magnitude of the variation that occurs when changing a variable over the others. Thus the case 16 was studied where the quantity of 2,800 pieces was recorded, respectively the highest profit. Finally, a comparison was made between two cases $\mathrm{A}$ and $\mathrm{B}$, the first one in which the effect of changing a variable was calculated, while the other was the effect of the simultaneous change of two variables. This allowed knowledge of the magnitude and intensity of the effect due to these changes.

\section{RESULTS AND DISCUSSION}

Using the data in Table 1 was represented in Fig. 1 the evolution of profit, total cost and sales revenues according to the quantities taken into study. 


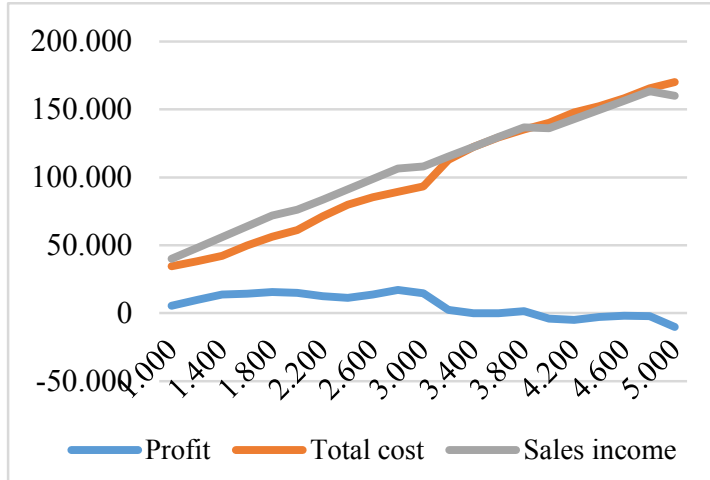

Fig. 1. Evolution of indicators according to the quantity.

From Fig. 1 analysis it is noted that up to 3,800 pieces of positive profit (higher incomes than costs) and from 4,000 pieces it becomes negative (loss).

Subsequently, taking into account the data in Table 1, it was observed that in case 16 there was a negative profit, and this value of 4000 RON was taken as a breakeven (i.e. the critical point). Figure 2 shows graphically expected sales and break-even sales.

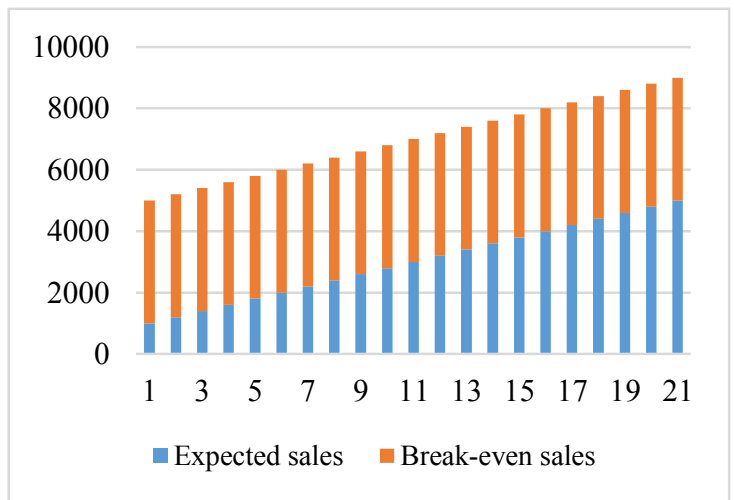

Fig. 2. Breaking point delimitation.

Using Eq. (2), the margin of safety was calculated and plotted in Figure 3.

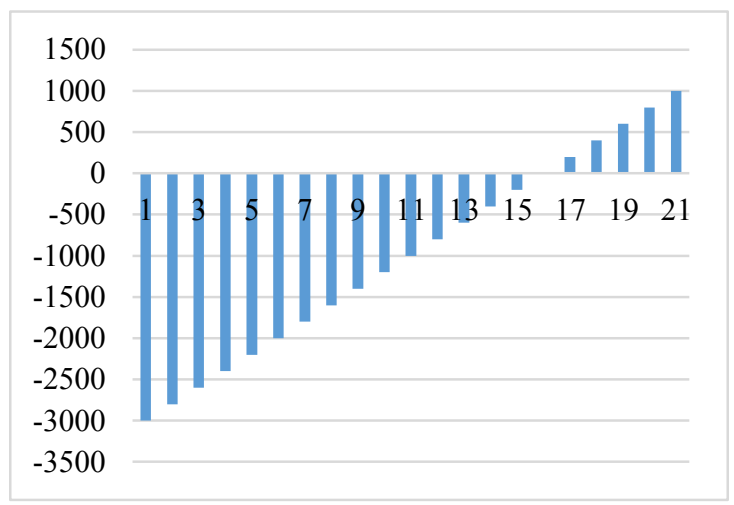

Fig. 3. Evolution of the margin of safety.

From the Fig. 3 analysis, it is noted that when the safety margin is negative (the expected sales are lower than the sales at the point of breaking) we say that the company is making profit.
Fig. 4 shows the evolution of the unit sale price, unit variable cost, and unit marginal contribution.

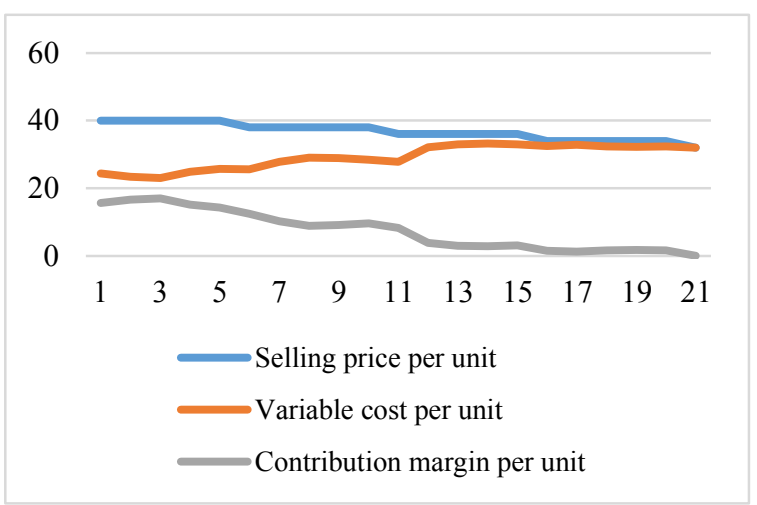

Fig. 4. Evolution of variables.

From the Fig. 4 analysis, it is observed that when the quantity increases (according to Table 1) the unit sale price and the unitary contribution margin decreases (reverse link) and the unitary variable cost increases (direct link).

In Table 2, the amount needed to be sold was calculated in order to obtain the expected profit.

Table 2. The distribution of the quantity according to the expected profit.

\begin{tabular}{|c|c|c|c|}
\hline $\begin{array}{c}\text { Profit } \\
{[\text { RON] }}\end{array}$ & $\begin{array}{c}\text { Total } \\
\text { fixed cost } \\
{[\text { RON] }}\end{array}$ & $\begin{array}{c}\mathrm{Cm} \\
\text { [RON/Pcs.] }\end{array}$ & $\begin{array}{c}\text { USNASP } \\
\text { [Pcs.] }\end{array}$ \\
\hline 5,600 & 10,000 & 15.60 & 1,000 \\
\hline 9,900 & 10,000 & 16.58 & 1,200 \\
\hline 13,700 & 10,000 & 16.93 & 1,400 \\
\hline 14,200 & 10,000 & 15.13 & 1,600 \\
\hline 15,700 & 10,000 & 14.28 & 1,800 \\
\hline 14,800 & 10,000 & 12.40 & 2,000 \\
\hline 12,400 & 10,000 & 10.18 & 2,200 \\
\hline 11,400 & 10,000 & 8.92 & 2,400 \\
\hline 13,600 & 10,000 & 9.08 & 2,600 \\
\hline 17,000 & 10,000 & 9.64 & 2,800 \\
\hline 14,600 & 10,000 & 8.20 & 3,000 \\
\hline 2,400 & 10,000 & 3.88 & 3,200 \\
\hline 100 & 10,000 & 2.97 & 3,400 \\
\hline
\end{tabular}

From Table 2 we can see that if we know the unitary contribution margin (the difference between the unit sale price and the unitary variable cost) and the fixed costs we can get the quantity to be sold to obtain the expected profit. It is noticed that the biggest profit is recorded in the quantity of 2,800 pieces (case 10 ).

To observe the influence of a variable on the other variables, the relative diminution of a variable, Case A (Table 3), and the relative diminution of two variables in the Case B (Table 4), were calculated.

Because for managers in economic and financial analyzes the profit is the indicator that determines the performance of a company, in Table 5 we obtained the relative deviation of the unitary variable cost on the profit. 
Table 3. The relative change of indicators according to the coefficient of variation (Case A).

\begin{tabular}{|c|c|c|c|c|}
\hline $\begin{array}{c}\text { Coefficient } \\
\text { of variation } \\
\text { [\%] }\end{array}$ & $\begin{array}{c}\text { Variable } \\
\text { cost } \\
\text { [RON] }\end{array}$ & $\begin{array}{c}\text { Total } \\
\text { cost } \\
\text { [RON] }\end{array}$ & $\begin{array}{c}\text { Sales } \\
\text { income } \\
\text { [RON] }\end{array}$ & $\begin{array}{c}\text { Profit } \\
\text { [RON] }\end{array}$ \\
\hline$-10 \%$ & $72,886.15$ & $82,886.15$ & $106,400.00$ & $23,513.85$ \\
\hline$-5 \%$ & $76,935.38$ & $86,935.38$ & $106,400.00$ & $19,464.62$ \\
\hline$-1 \%$ & $80,174.77$ & $90,174.77$ & $106,400.00$ & $16,225.23$ \\
\hline $0 \%$ & $80,984.62$ & $90,984.62$ & $106,400.00$ & $15,415.38$ \\
\hline $1 \%$ & $81,794.46$ & $91,794.46$ & $106,400.00$ & $14,605.54$ \\
\hline $5 \%$ & $85,033.85$ & $95,033.85$ & $106,400.00$ & $11,366.15$ \\
\hline $10 \%$ & $89,083.08$ & $99,083.08$ & $106,400.00$ & $7,316.92$ \\
\hline $\begin{array}{c}\text { Coefficient } \\
\text { of variation }\end{array}$ & Profit & $\begin{array}{c}\text { Variable } \\
\text { cost }\end{array}$ & $\begin{array}{c}\text { Total } \\
\text { cost }\end{array}$ & $\begin{array}{c}\text { Sales } \\
\text { income }\end{array}$ \\
\hline$-10 \%$ & $15,300.00$ & $80,984.62$ & $90,984.62$ & $106,284.62$ \\
\hline$-5 \%$ & $16,150.00$ & $80,984.62$ & $90,984.62$ & $107,134.62$ \\
\hline$-1 \%$ & $16,830.00$ & $80,984.62$ & $90,984.62$ & $107,814.62$ \\
\hline $0 \%$ & $17,000.00$ & $80,984.62$ & $90,984.62$ & $107,984.62$ \\
\hline $1 \%$ & $17,170.00$ & $80,984.62$ & $90,984.62$ & $108,154.62$ \\
\hline $5 \%$ & $17,850.00$ & $80,984.62$ & $90,984.62$ & $108,834.62$ \\
\hline $10 \%$ & $18,700.00$ & $80,984.62$ & $90,984.62$ & $109,684.62$ \\
\hline $\begin{array}{c}\text { Coefficient } \\
\text { of variation }\end{array}$ & $\begin{array}{c}\text { Sales } \\
\text { income }\end{array}$ & Profit & $\begin{array}{c}\text { Total } \\
\text { cost }\end{array}$ & $\begin{array}{c}\text { Variable } \\
\text { cost }\end{array}$ \\
\hline$-10 \%$ & $95,760.00$ & $17,000.00$ & $78,760.00$ & $68,760.00$ \\
\hline$-5 \%$ & $101,080.00$ & $17,000.00$ & $84,080.00$ & $74,080.00$ \\
\hline$-1 \%$ & $105,336.00$ & $17,000.00$ & $88,336.00$ & $78,336.00$ \\
\hline $0 \%$ & $106,400.00$ & $17,000.00$ & $89,400.00$ & $79,400.00$ \\
\hline $1 \%$ & $107,464.00$ & $17,000.00$ & $90,464.00$ & $80,464.00$ \\
\hline $5 \%$ & $111,720.00$ & $17,000.00$ & $94,720.00$ & $84,720.00$ \\
\hline $10 \%$ & $117,040.00$ & $17,000.00$ & $100,040.00$ & $90,040.00$ \\
\hline & & & & \\
\hline & & &
\end{tabular}

Table 4. The relative change of indicators according to the coefficient of variation (Case B).

\begin{tabular}{|c|c|c|c|}
\hline $\begin{array}{c}\text { Coefficient } \\
\text { of variation } \\
{[\%]}\end{array}$ & $\begin{array}{c}\text { Total } \\
\text { cost } \\
{[\text { RON] }}\end{array}$ & $\begin{array}{c}\text { Sales } \\
\text { income } \\
{[\text { RON] }}\end{array}$ & $\begin{array}{c}\text { Profit } \\
\text { [RON] }\end{array}$ \\
\hline$-10 \%$ & $82,886.15$ & $95,760.00$ & $12,873.85$ \\
\hline$-5 \%$ & $86,935.38$ & $101,080.00$ & $14,144.62$ \\
\hline$-1 \%$ & $90,174.77$ & $105,336.00$ & $15,161.23$ \\
\hline $0 \%$ & $90,984.62$ & $106,400.00$ & $15,415.38$ \\
\hline $1 \%$ & $91,794.46$ & $107,464.00$ & $15,669.54$ \\
\hline $5 \%$ & $95,033.85$ & $111,720.00$ & $16,686.15$ \\
\hline $10 \%$ & $99,083.08$ & $117,040.00$ & $17,956.92$ \\
\hline $\begin{array}{c}\text { Coefficient } \\
\text { of variation }\end{array}$ & Profit & $\begin{array}{c}\text { Total } \\
\text { cost }\end{array}$ & $\begin{array}{c}\text { Sales } \\
\text { income }\end{array}$ \\
\hline$-10 \%$ & $15,300.00$ & $72,886.15$ & $82,886.15$ \\
\hline$-5 \%$ & $16,150.00$ & $76,935.38$ & $86,935.38$ \\
\hline$-1 \%$ & $16,830.00$ & $80,174.77$ & $90,174.77$ \\
\hline $0 \%$ & $17,000.00$ & $80,984.62$ & $90,984.62$ \\
\hline $1 \%$ & $17,170.00$ & $81,794.46$ & $91,794.46$ \\
\hline $5 \%$ & $17,850.00$ & $85,033.85$ & $95,033.85$ \\
\hline $10 \%$ & $18,700.00$ & $89,083.08$ & $99,083.08$ \\
\hline $\begin{array}{c}\text { Coefficient } \\
\text { of variation }\end{array}$ & $\begin{array}{c}\text { Sales } \\
\text { income }\end{array}$ & Profit & $\begin{array}{c}\text { Total } \\
\text { cost }\end{array}$ \\
\hline$-10 \%$ & $95,760.00$ & $15,300.00$ & $80,460.00$ \\
\hline$-5 \%$ & $101,080.00$ & $16,150.00$ & $84,930.00$ \\
\hline$-1 \%$ & $105,336.00$ & $16,830.00$ & $88,506.00$ \\
\hline $0 \%$ & $106,400.00$ & $17,000.00$ & $89,400.00$ \\
\hline $1 \%$ & $107,464.00$ & $17,170.00$ & $90,294.00$ \\
\hline $5 \%$ & $111,720.00$ & $17,850.00$ & $93,870.00$ \\
\hline $10 \%$ & $117,040.00$ & $18,700.00$ & $98,340.00$ \\
\hline & & \multicolumn{2}{|c}{} \\
\hline
\end{tabular}

Table 5. Relative deviation of the variables on profit.

\begin{tabular}{|c|c|c|c|c|c|}
\hline \multirow{2}{*}{$\begin{array}{c}\Delta \text { Variable } \\
\text { cost }\end{array}$} & \multirow[b]{2}{*}{$\begin{array}{c}\Delta \text { Total } \\
\text { cost }\end{array}$} & \multicolumn{2}{|c|}{ Case A } & \multicolumn{2}{|c|}{ Case B } \\
\hline & & \begin{tabular}{|l|}
$\Delta$ Sales \\
income
\end{tabular} & $\Delta$ Profit & $\begin{array}{l}\Delta \text { Sales } \\
\text { income }\end{array}$ & $\Delta$ Profit \\
\hline$-10 \%$ & $-8.90 \%$ & \begin{tabular}{|l|}
0 \\
\end{tabular} & $52.53 \%$ & $-10 \%$ & $-16.49 \%$ \\
\hline$-5 \%$ & $-4.45 \%$ & 0 & $26.27 \%$ & $-5 \%$ & $-8.24 \%$ \\
\hline$-1 \%$ & $-0.89 \%$ & 0 & $5.25 \%$ & $-1 \%$ & $-1.65 \%$ \\
\hline $0 \%$ & $0.00 \%$ & 0 & $0.00 \%$ & $0 \%$ & $0.00 \%$ \\
\hline $1 \%$ & $0.89 \%$ & 0 & $-5.25 \%$ & $1 \%$ & $1.65 \%$ \\
\hline $5 \%$ & $4.45 \%$ & 0 & $-26.27 \%$ & $5 \%$ & $8.24 \%$ \\
\hline $10 \%$ & $8.90 \%$ & 0 & $-52.53 \%$ & $10 \%$ & $16.49 \%$ \\
\hline
\end{tabular}

From the analysis of Table 5 for Case $\mathrm{A}$ it is observed that when the variable cost changes, it will change in the same direction but with a smaller weight and the total cost (the difference is given by the fixed cost) and the profit will change in the sense the opposite (lower costs increase profit and vice versa) but in a much bigger share. Table 5 for the Case B shows that the change in variable costs and sales revenue causes a change in the same sense of profit, which is close to size.

Table 6 shows the percentage changes in sales revenue for Case A and Case B when the total cost does not change or change with the same percentage as the profit.

Table 6. The relative deviation of the variables on sales income.

\begin{tabular}{|c|c|c|c|c|}
\hline \multirow{2}{*}{$\Delta$ Profit } & \multicolumn{2}{|c|}{ Case A } & \multicolumn{2}{c|}{ Case B } \\
\cline { 2 - 5 } & $\begin{array}{c}\Delta \text { Total } \\
\text { cost }\end{array}$ & $\begin{array}{c}\Delta \text { Sales } \\
\text { income }\end{array}$ & $\begin{array}{c}\Delta \text { Total } \\
\text { cost }\end{array}$ & $\begin{array}{c}\Delta \text { Sales } \\
\text { income }\end{array}$ \\
\hline$-10 \%$ & 0 & $-1.57 \%$ & $-10 \%$ & $-9.07 \%$ \\
\hline$-5 \%$ & 0 & $-0.79 \%$ & $-5 \%$ & $-4.54 \%$ \\
\hline$-1 \%$ & 0 & $-0.16 \%$ & $-1 \%$ & $-0.91 \%$ \\
\hline $0 \%$ & 0 & $0.00 \%$ & $0 \%$ & $0.00 \%$ \\
\hline $1 \%$ & 0 & $0.16 \%$ & $1 \%$ & $0.91 \%$ \\
\hline $5 \%$ & 0 & $0.79 \%$ & $5 \%$ & $4.54 \%$ \\
\hline $10 \%$ & 0 & $1.57 \%$ & $10 \%$ & $9.07 \%$ \\
\hline
\end{tabular}

The analysis of Table 6 can be seen in the Case A that the change of profit when the total cost is maintained at the same level leads to the same change of the sales revenues. In the Case B when the same changes in profit and total cost occur, they will cause a change in sales revenue of approximately the same level.

Table 7 shows the percentage changes in the total cost in in the Case A and in the Case B when we change

Table 7. Relative change of variables on total cost.

\begin{tabular}{|c|c|c|c|c|}
\hline \multirow{2}{*}{$\begin{array}{c}\Delta \text { Sales } \\
\text { income }\end{array}$} & \multicolumn{2}{|c|}{ Case A } & \multicolumn{2}{c|}{ Case B } \\
\hline$-10 \%$ & 0 & $-11.90 \%$ & $-10 \%$ & $-11.26 \%$ \\
\hline$-5 \%$ & 0 & $-5.95 \%$ & $-5 \%$ & $-5.63 \%$ \\
\hline$-1 \%$ & 0 & $-1.19 \%$ & $-1 \%$ & $-1.13 \%$ \\
\hline $0 \%$ & 0 & $0.00 \%$ & $0 \%$ & $0.00 \%$ \\
\hline $1 \%$ & 0 & $1.19 \%$ & $1 \%$ & $1.13 \%$ \\
\hline $5 \%$ & 0 & $5.95 \%$ & $5 \%$ & $5.63 \%$ \\
\hline $10 \%$ & 0 & $11.90 \%$ & $10 \%$ & $11.26 \%$ \\
\hline
\end{tabular}


to only one variable (sales income) or when there is a change to two variables (sales and profit).

The analysis of Table 7 shows that in the Case A, when sales revenue changes and profit remains the same it will cause a change in the same sense of the total cost but at a higher level. In the Case B we have two variables that change in the same direction and at the same level that cause a variation of profit at a lower level.

Fig. 5 (Case A) shows the evolution of profit when the variable cost changes and the amount (2,800 pieces) and sales revenue (106,400 RON) remain unchanged.

Fig. 5 (Case B) shows the evolution of profit when both variables (unit variable cost and sales revenue) change with the stated percentages.

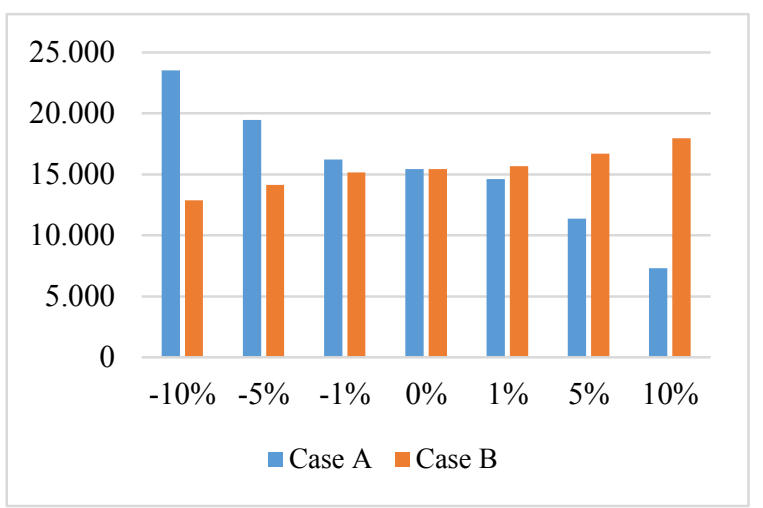

Fig. 5. Evolution of profit

From the analysis of Case A, it can be seen that when the unitary variable cost increases the profit decreases. From the analysis of Case B, it can be seen that when the quantity, unitary cost and sales revenue increase with the same percentages and the profit will increase the same. From the comparison between Case A and Case B, we can see that the effect produced by an indicator (unitary variable cost) has higher consequences for the total cost and implicitly for the profit than for the total variable cost product and the quantity on the profit.

Fig. 6 shows the evolution of sales revenue when the quantity and profit vary or when the quantity, profit, and total cost varies with the specified percentages. From Case A, it is noted that when profit changes and total quantity and cost remain unchanged then sales revenue is the difference. The analysis of Case B shows that when all variables change with the same percentages it causes a change in the same direction and with the same percentage of sales revenue. By comparison, it is noticed that the effect of changing a variable is smaller than the order of magnitude than the one produced by all the variables.

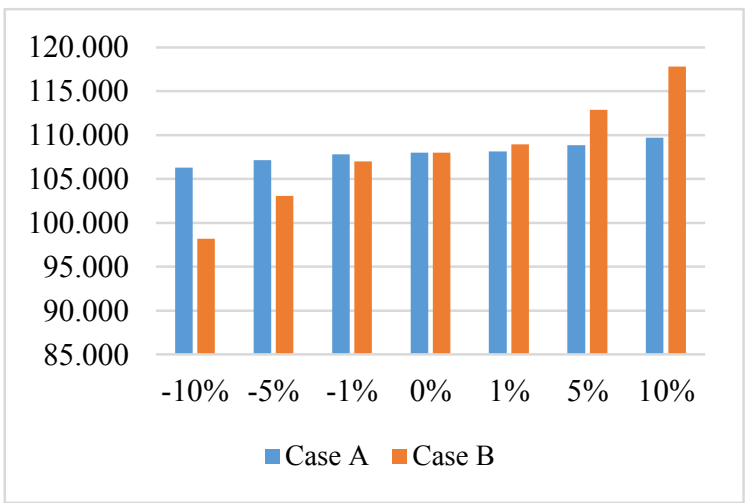

Fig. 6. Evolution of sales income

Fig. 7 shows the evolution of total cost when sales quantity and sales (Case A), quantity, sales revenue and profit varies (Case B).

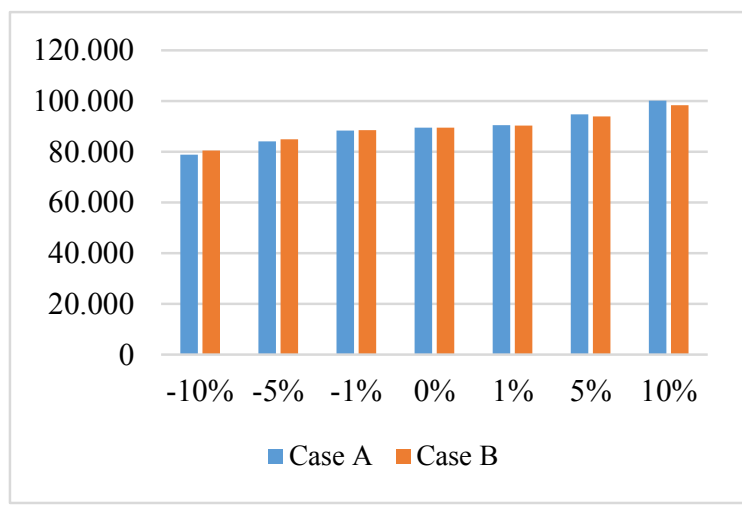

Fig. 7. Evolution of total cost

From the analysis of Case A, it can be seen that the change in the sales revenues determines the total cost changes in the same direction when it is desired that the profit $(17,000 \mathrm{RON})$ and the quantity (2,800 pieces) remain at the same level. Case B shows that the increase in total cost is determined by the increase in quantity, unitary cost, and profit. The effect determined by the variation obtained on the total cost is higher in Case A than in Case B.

\section{CONCLUSIONS}

The Cost-Volume-Profit Analysis has allowed you to calculate the breaking point, safety margin and sales expected. Subsequently, the evolution of some indicators (unitary variable cost, unit selling price, unitary marginal contribution) to the volume change of the production, according to some cases taken into the study, was calculated and observed. Activity-related fluctuations have demonstrated chain changes in unit costs and implicitly in sales prices.

In fact, the changes are not only related to the volume of activity and these are also given by the other variables: production costs, the selling price accepted by the market, the profit obtained differently from the expected, etc. 
The sensitivity analysis allowed the change of variance to be determined when a change occurs at the level of a single variable or when it affects two variables. Although production costs decrease as a result of economies of scale and can be achieved as the quantity increases (due to fixed costs and less of the variable costs), in practice it is found that they do not propagate in the same proportions. Similarly, if there is a change in the sales mix, the earnings will show changes in the amount sold.

The disadvantage of these analyzes can be given by the uncertainty that exists in certain activities of correctly dividing fixed and variable costs. In reality, some fixed costs may be semi-fixed or may be transformed from a certain level of activity into variable costs. Splitting costs into fixed and variable costs is sometimes difficult. Profit can be predicted on the basis of variable cost, or vice versa if a certain level of profit is desired, then either the sales revenue in the sense of maximizing or the minimization costs.

I consider that the use of CVP analysis and sensitivity analysis in forecasting, tracking, and control activity will result in an efficient optimization of costbenefit, profit and profitability indicators as a result of both anticipative and participatory management. Knowing activity through these analyzes will be a useful tool for managers, providing the enterprise with the ability to adapt and respond to changes in the environment.

\section{References}

1. S. Liebesman, How to manage risk in a global economy, QP, 41 (3), p. 58-60 (2008).

2. R. Balakrishnan, E. Labro, N.S. Soderstrom, Cost structure and sticky costs, J. of Manag. Acc. Res., 26 (2), 91-116 (2014).

3. T. Groot, F. Selto, Advanced management accounting, Pearson Education, Amsterdam (2013).

4. S.W. Anderson, Measuring the impact of product mix heterogeneity on manufacturing cost, The Acc. Rev., 79, 363-387 (1995).

5. R.S. Kaplan, R. Cooper, Cost and effect: sing integrated cost systems to drive profitability and performance, Harvard Business School Press, Boston (1998).

6. J. Glomazić, Influence of operating conditions to the method of calculating cost prices, J. of Acc. and Manag., 2016, 6 (2), 43 - 54.

7. J.G. Miller, T.E. Vollman, The hidden factory, Harv. Bus. Rev., 63, 142-150 (1985).
8. H.T. Johnson, R.S. Kaplan, Relevance lost: The rise and fall of management accounting, Harvard Business School Press, Washington, DC (1987).

9. R.D. Banker, G. Potter, R.G. Schroeder, An empirical analysis of manufacturing overhead cost drivers, J. of Acc. and Ec., 19, 115-137 (1995).

10. D. Teece, M. Peteraf, S. Leih, Dynamic capabilities and organizational agility: Risk, uncertainty, and strategy in the innovation economy, California Manag. Rev., 58 (4), 13-35 (2016).

11. C. Drury, M. Tayles, Cost system design and profitability analysis in UK companies, Chartered Institute of Management Accountants, London (2000).

12. C.T. Horngren, S.M. Datar, and M. Rajan, Cost Accounting: A Managerial Emphasis, 15th edition Harlow, U.K.: Pearson Education Limited (2015).

13. Ernst \& Young, Global transfer pricing survey - Addressing the challenges of globalization, New York, NY: Ernst \& Young Ltd. (2010).

14. R.S. Kaplan, A. Atkinson, Advanced management accounting, 3rd edition Englewood Cliffs, NJ: Prentice Hall (1998).

15. S. Sahay, Transfer pricing based on actual cost, J. of Man. Acc. Res., 15, 177-192 (2003).

16. K.A. Merchant,d W.A. Van der Stede, Management control systems: Performance measurement, evaluation and incentive, 3rd edition Harlow, U.K.: Financial Times Prentice Hall (2012).

17. J.L. Zimmerman, Accounting for decision making and control, 8th edition New York, NY: McGraw-Hill Companies Inc. (2013).

18. M. Anderson, R. Banker, S. Janakiraman, Are selling, general, and administrative costs „sticky“?, J. of Acc. Res., 41, p. 47-63 (2003).

19. K. Calleja, M. Steliaros, D.C. Thomas, A note on cost stickiness: Some international comparisons, Manag. Acc. Res., 17, 127-140.

20. R.D. Banker, L.T. Chen, Predicting earnings using a model based on cost variability and cost stickiness, The Acc. Rev., 81 (2), 285-307 (2006).

21. M. Potkany, L. Krajcirova, Quantification of the volume of products to achieve the BreakEven Point and desired profit in nonhomogeneous production, Proc. Ec. and Fin., 26, 194 - 201 (2015). 